\title{
Effect of sintering temperature on structural and electrical switching properties of cadmium ferrite
}

\author{
S.P. Dalawai ${ }^{\star}{ }^{\star}$, A.B. Gadkari ${ }^{2}$, T.J. Shinde ${ }^{3}$, P.N. Vasambekar ${ }^{1}$ \\ ${ }^{1}$ Department of Electronics, Shivaji University Kolhapur 416 004, India \\ ${ }^{2}$ Department of Physics, GKG college, Kolhapur 416012 , India \\ ${ }^{3}$ Department of Physics, Smt KRP Kanya Mahavidyalaya Islampur 416 409, India
}

*Corresponding author. Tel: (+91) 9890253825; E-mail: sanjeevdalawai@ gmail.com

Received: 01 October 2012, Revised: 12 December 2012 and Accepted: 07 January 2013

\section{ABSTRACT}

Cadmium ferrite was prepared by standard ceramic method and characterized by XRD, IR and SEM techniques. The X-ray analysis confirms the formation of single phase cubic spinel structure. The lattice constant decreases slightly and porosity increases with increase in sintering temperature. The crystallite size of the samples lies in the range of 22.83 to $24.44 \mathrm{~nm}$. The IR study shows two absorption bands around $400 \mathrm{~cm}^{-1}$ and $600 \mathrm{~cm}^{-1}$ corresponding to octahedral and tetrahedral sites respectively. The grain size increases and switching field decreases with increases in sintering temperature. Copyright $@ 2013$ VBRI press.

Keywords: Cadmium ferrite; grain size; structural; electrical switching.
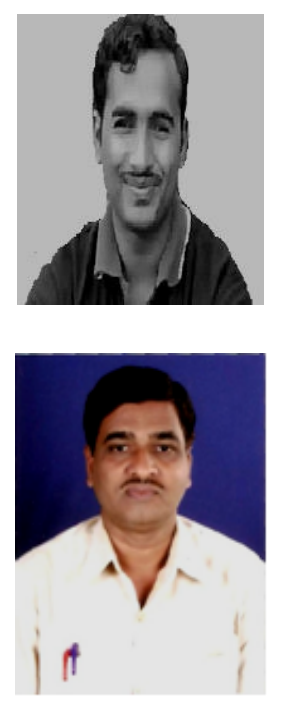

Sanjeev P. Dalawai is currently doing Ph.D in Department of Physics, Shivaji University Kolhapur. His fields of interest are structural, electrical, switching and ferrite gas sensing properties for gases like $\mathrm{LPG}, \mathrm{C}_{2} \mathrm{H}_{5} \mathrm{OH}$, and $\mathrm{Cl}_{2}$.

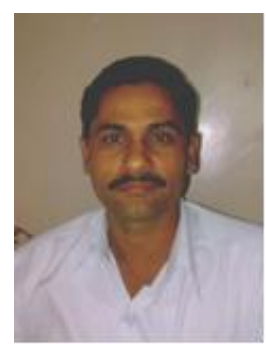

Ashok Gadkari has obtained his M.Sc. and M. Phil. degree in 1983 and 1988 from SUK, Kolhapur. Presently he is Associate Prof. and head of department of physics. His field of research is synthesis of ferrite materials for structural, electric, magnetic, humidity and gas sensing properties at G K G college, Kolhapur. He has published 30 research paper in Journal.

T. J. Shinde has obtained his M.Sc. and M.Phil drgree in 1990 and 2001 from SUK, Kolhapur. Presently he is Associate Professor and working on ferrites for electromagnetic wave and gas sensors in KRP kanya mahavidyalaya, Islampur. He has published 15 research articles in various scientific journals.

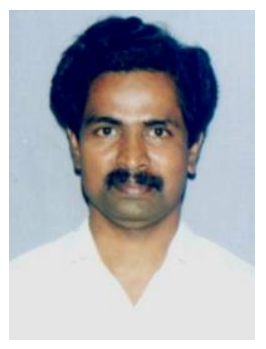

Pramod N. Vasambekar is Professor of electronics. He is working on soft ferrites, humidity and gas sensors, microwaves and communication electronics in Shivaji University Kolhapur. He has contributed 35 research papers in journals and 33 papers in the international and national conferences. 


\section{Introduction}

The structural, electrical, magnetic and electrical switching properties of cadmium ferrite have been already studied [13]. Its applications in the field of magneto-optical and gas sensors are reported $[\mathbf{4}, \mathbf{5}]$. Cadmium ferrite has a normal spinel structure [6]. The solid-solid reaction between $\mathrm{CdO}$ and $\mathrm{Fe}_{2} \mathrm{O}_{3}$ takes place at a temperature about $600^{\circ} \mathrm{C}$ gives $\mathrm{CdFe}_{2} \mathrm{O}_{4}$ of moderate degree of crystallinity [7]. Nayak et al. [8] reported increment in particle size with increase in temperature. The sintering temperature effect is studied by Islam et al. [9] of Ni-Zn ferrite and showed that the sintering temperature is mainly affects the permeability, density, grain size and Curie temperature. At the higher sintering temperature, density gets decreased due to increase in intra-granular porosity resulting from the discontinuous in the grain growth. Electrical switching phenomenon was first reported by Yamashiro et al. [10] in $\mathrm{CuFe}_{2} \mathrm{O}_{4}$ and simultaneously studied by Vaingaonkar et al. [11] in polycrystalline for bulk $\mathrm{CuFe}_{2} \mathrm{O}_{4}$. Further switching phenomenon in ferrites were reported by Histake et al. [12], Sagare et al. [3] by Li-Cd ferrites, Miller et al. [13] by $\mathrm{Ni}$ ferrite and Babbitt et al. [14] by Lithium ferrites and showed that grain size depends on switching property. $\mathrm{Mg}$ $\mathrm{Mn}$ ferrites core are studied by Tancrell et al. [15]. $\mathrm{Cd}_{\mathrm{x}} \mathrm{Co}_{1-}$ ${ }_{x} \mathrm{Fe}_{2-\mathrm{y}} \mathrm{Cr}_{\mathrm{y}} \mathrm{O}_{4}$ system is studied by Vasambekar et al. [16]. The CCNR type of high field instability in $\mathrm{Ti}^{+4}$ substituted $\mathrm{Mn}-\mathrm{Zn}$ ferrites are reported by Saija et al. [17] and they showed that switching field increases with increase in $\mathrm{Ti}^{4+}$ content. Electrical switching properties of $\mathrm{Cr}^{3+}$ and $\mathrm{Al}^{3+}$ substituted $\mathrm{NiFe}_{2} \mathrm{O}_{4}$ were reported by Patange et al. [18, 19]. The current-voltage (I-V) characteristics of single $\mathrm{SnO}_{2}$ nanowire measured at different temperatures [20]. The ferrite switching materials are mostly used in different applications such as computer cable, microelectronics and data storage etc [14-19]. Kiri et al. reviewed the solid state thermochromic materials are studied and show that the intelligent thermochromic glass require switching temperatures between $18-25^{\circ} \mathrm{C}$ [21].

In the present communication we report the effect of sintering temperature on structural and electrical switching properties of cadmium ferrite.

\section{Experimental}

\section{Ferrite sample preparation}

The $\mathrm{CdFe}_{2} \mathrm{O}_{4}$ was prepared by standard ceramic method. The AR grade cadmium oxide $99.5 \%$ (Hi Media) and ferrous oxide $98 \%$ (Thomas baker) were weighed as per stoichiometric proportion. They were mixed in agate mortar with acetone and milled in $1 / 2$ hrs. The mixture was then put into temperature controlled Muffle furnace for 6 hours at $600^{\circ} \mathrm{C}$ for pre-sintering. After furnace cooling the powder was again milled in agate mortar of $1 / 2 \mathrm{hrs}$ with acetone base. The powders were put into furnace and sintered at three different temperatures $900^{\circ} \mathrm{C}, 1000^{\circ} \mathrm{C}$ and $1100^{\circ} \mathrm{C}$ for 10 hours and after furnace cooled. The powder was again milled with acetone base. Using 5\% poly vinyl alcohol the powder was pressed under hydraulic press with the pressure is 6 ton $/ \mathrm{cm}^{2}$ for 5 minutes to form $10 \mathrm{~mm}$ diameter pellet. Finally the pellets were sintered for 6 hours at different sintering temperatures. The cooling and heating rate of the furnace is at $80^{\circ} \mathrm{C}$ per hour. The physical density of the sample was investigated by the Archimedes principle.

\section{Characterization techniques}

The X-ray diffraction patterns were recorded at step size of 0.02 in angular range $10^{\circ}-100^{\circ}(2 \theta)$ at $40 \mathrm{kV}$ and $25 \mathrm{~mA}$ with $\mathrm{Cr}-\mathrm{K} \alpha$ radiation $\left(\lambda=2.29165 \mathrm{~A}^{\circ}\right)$ using Philips PW3710 X-ray powder diffractometer. FT-IR spectrum was recorded in the range of $350-800 \mathrm{~cm}^{-1}$ using Perkin-Elmer spectrum one spectrophotometer (USA) using $\mathrm{KBr}$ pellet technique. SEM was carried to analyze microstructure of fractured surfaces of the pellets on JEO JSM 6360 SEM (Japan) at 10000 magnifications.

\section{Electrical switching}

Electrical switching was recorded at room temperature using Aplab high voltage dc power supply and Meca $81 \mathrm{~K}$ multimeter. The electrical switching of sample was recorded with the help of silver foil connecting wires of conducting cell.

\section{Results and discussion}

The X-ray diffraction patterns of cadmium ferrite sintered at three different temperatures $\left(900^{\circ} \mathrm{C}, 1000^{\circ} \mathrm{C}\right.$ and $\left.1100^{\circ} \mathrm{C}\right)$ under investigation are presented in Fig. 1. The XRD confirms the formation of single phase cubic spinel structure in all the samples. The presence of (220), (311), (422), (333) and (440) planes were observed. The Xdiffraction patterns agree with JCPDS card number-020975. Lattice constant of sintered cadmium ferrites under investigation was calculated using the Bragg's equation [22],

$$
\mathrm{a}=\mathrm{d}_{\mathrm{hkl}} \sqrt{\mathrm{h}^{2+} \mathrm{k}^{2}+\mathrm{l}^{2}}
$$

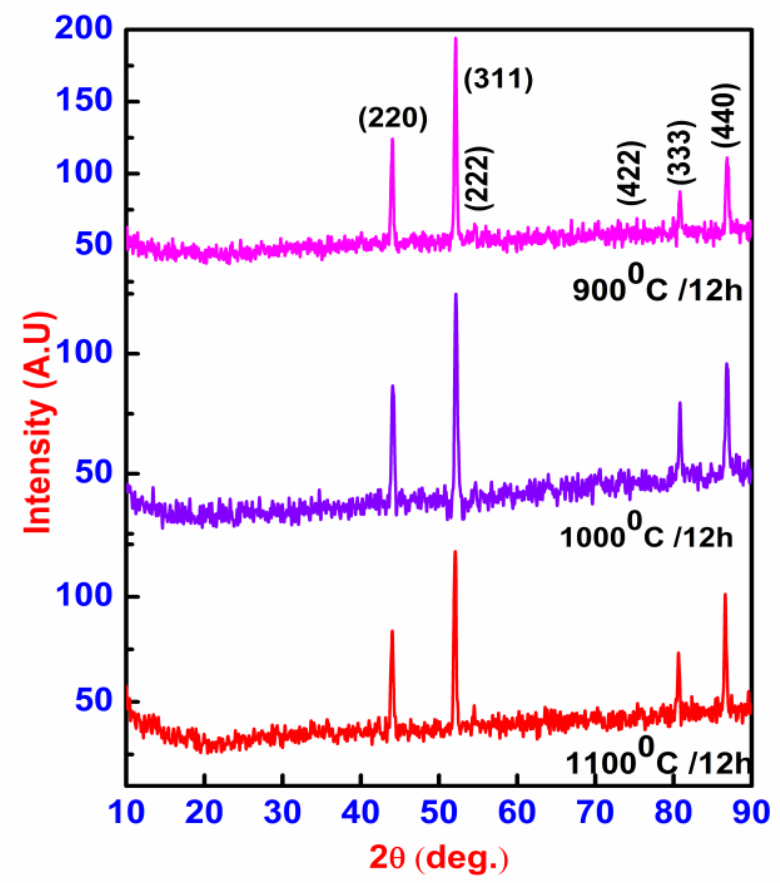

Fig. 1. XRD of Cd ferrite sintered at $\left(900^{\circ} \mathrm{C}, 1000^{\circ} \mathrm{C}\right.$ and $\left.1100^{\circ} \mathrm{C}\right)$. 
Table 1. Structural parameters and electrical switching field for $\mathrm{Cd}$ ferrite sintered at $900^{\circ} \mathrm{C}, 1000^{\circ} \mathrm{C}, 1100^{\circ} \mathrm{C}$.

\begin{tabular}{|c|c|c|c|c|c|c|c|c|c|}
\hline \multirow{2}{*}{$\begin{array}{l}\text { Sintering } \\
\text { temperature } \\
\left({ }^{0} \mathrm{C}\right)\end{array}$} & \multirow{2}{*}{$\begin{array}{l}\text { Lattice } \\
\text { constant } \\
\left(\mathrm{A}^{0}\right)\end{array}$} & \multirow{2}{*}{$\begin{array}{l}\text { Crystallite } \\
\text { size } \\
(\mathrm{nm})\end{array}$} & \multirow{2}{*}{$\begin{array}{l}\text { Grain } \\
\text { size } \\
(\mu \mathrm{m})\end{array}$} & \multirow{2}{*}{$\begin{array}{l}\text { X-ray } \\
\text { density } \\
\left(\mathrm{g} / \mathrm{cm}^{3}\right)\end{array}$} & \multirow{2}{*}{$\begin{array}{l}\text { Physical } \\
\text { density } \\
\left(\mathrm{g} / \mathrm{cm}^{3}\right)\end{array}$} & \multirow{2}{*}{$\begin{array}{l}\text { Porosity } \\
(\%)\end{array}$} & \multirow{2}{*}{$\begin{array}{l}\text { Electrical } \\
\text { field } \\
(\mathrm{V} / \mathrm{cm})\end{array}$} & \multicolumn{2}{|c|}{$\begin{array}{l}\text { Absorption } \\
\text { band. }\left(\mathrm{cm}^{-1}\right)\end{array}$} \\
\hline & & & & & & & & $v_{1}$ & $v_{2}$ \\
\hline $900^{\circ} \mathrm{C}$ & 8.705 & 38.6 & 1.10 & 5.828 & 5.326 & 09.42 & 4600 & 575 & 435 \\
\hline $1000^{\circ} \mathrm{C}$ & 8.700 & 36.2 & 1.26 & 5.835 & 5.269 & 10.70 & 4200 & 578 & 438 \\
\hline $1100^{\circ} \mathrm{C}$ & 8.687 & 42.3 & 1.32 & 5.837 & 5.254 & 11.09 & 3200 & 576 & 436 \\
\hline
\end{tabular}

where, $d_{h k l}$ is the interplanner distance and $(h, k, 1)$ are the Miller indices of planes. The calculated lattice constants are presented in Fig. 2. From this figure, the lattice constant decreases slightly with increase in sintering temperature. Mostafa et al. [7] reported similar results for cadmium ferrite. The average crystallite size of the samples was calculated from the most intense (311) peak of XRD by using Debye Scherer equation [23].

$$
\mathrm{D}=\frac{0.94 \lambda}{\beta \cos \theta}
$$

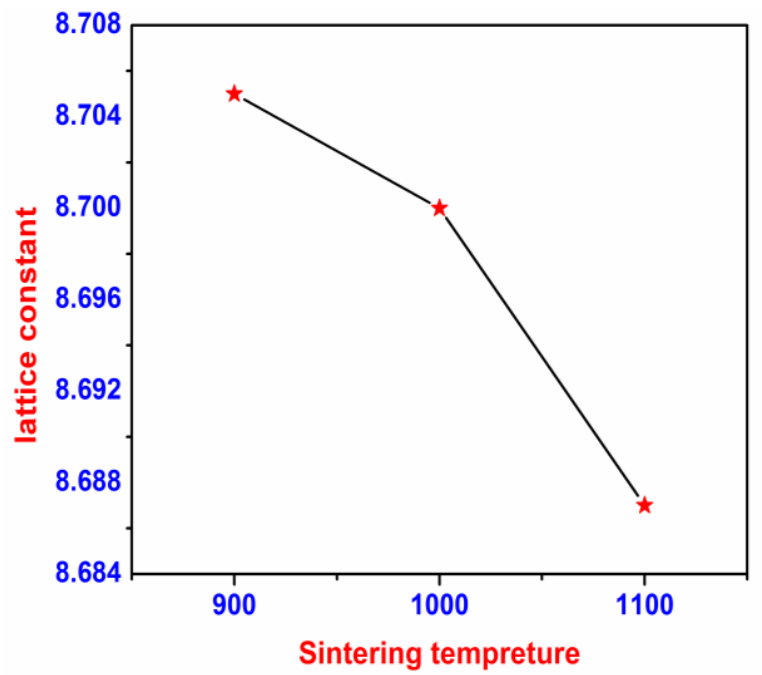

Fig. 2. Variation of lattice constant with sintering temperature.

Where $\lambda$ is the wave length of $X$-rays, $\beta$ is the full width half maximum (FWHM) and $\theta$ is the Bragg's angle. The average crystallite size lies in the range 36.2 to $42.3 \mathrm{~nm}$ and is presented in Table 1. These results are in good agreement with results reported by Nayak et al. [8]. The variation of X-ray density and physical density of all samples at different sintering conditions are presented in the Table 1. The X-ray density values are slightly larger than the physical density this is because of mass to volume ratio. Table 1 shows that porosity increases with the increase in sintering temperature. The porosity is of two type, one is intragranular porosity and another is intergranular porosity; the intragranular porosity get increases with increase in higher sintering temperature due to discontinuous grain growth [9].
The IR spectra shows two major absorption bands near $400 \mathrm{~cm}^{-1}$ and $600 \mathrm{~cm}^{-1}$ corresponding to octahedral and tetrahedral sites respectively. The IR spectra for all samples under investigation are presented in Fig 3. In bulk $\mathrm{Cd}$ ferrite similar results are reported by Desai et al [2]. The values of absorption bands $\left(v_{1}\right.$ and $\left.v_{2}\right)$ corresponding to tetrahedral and octahedral sites are presented in Table 1.

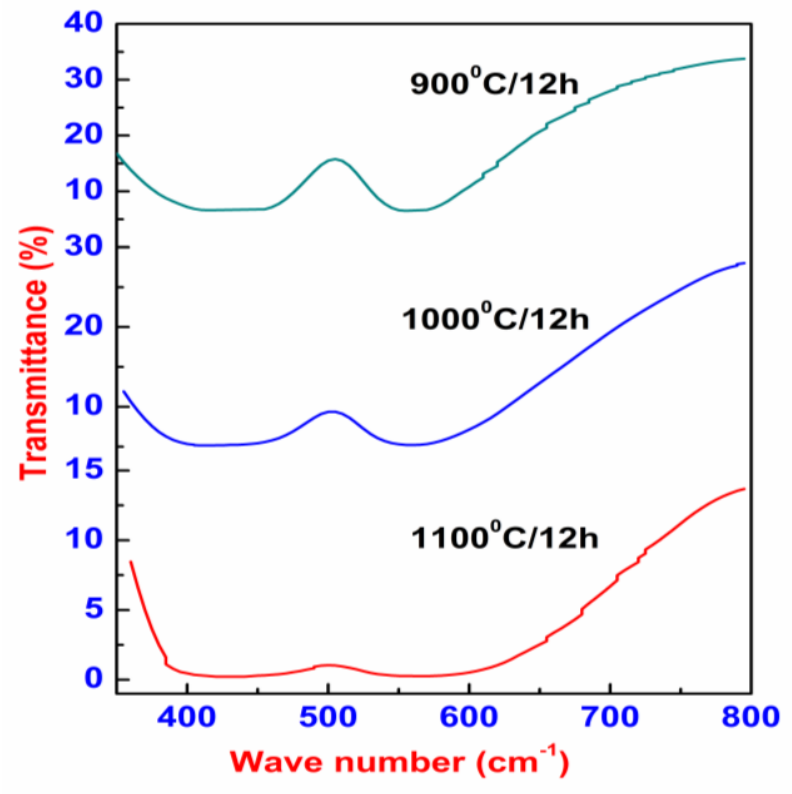

Fig. 3. IR of Cd ferrite sintering at $900^{\circ} \mathrm{C}, 1000^{\circ} \mathrm{C}$ and $1100^{\circ} \mathrm{C}$.

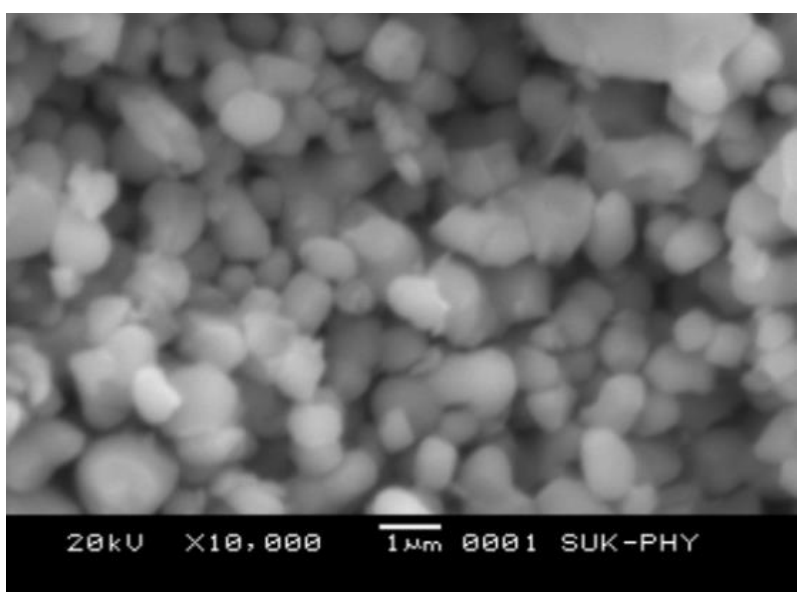

Fig. 4. Typical micrograph of $\mathrm{Cd} \mathrm{Fe}_{2} \mathrm{O}_{4}$ sintered at $1000^{\circ} \mathrm{C}$. 
The microphotographs of fractured surfaces of pellets under investigation are presented in Fig. 4. The grain size was calculated by linear intercept method [24].

$$
\mathrm{G}_{\mathrm{a}}=\frac{1.5 \mathrm{~L}}{\mathrm{MN}}
$$

The morphology of particle structure is almost spherical and regular in shape and is uniformly dispersed. The grain size of the samples increases with increase in sintering temperature. It is due to the increase in density with increasing sintering temperature [9].

The plot of current against dc electric field for samples under investigation is presented in Fig. 5. From this figure it can be noticed that the CCNR type electrical switching is observed in the samples under investigation. The curves shows that, it linearly increases up to $5 \mathrm{~mA}$ then current increases quickly and switch the sample with increases in current and decreases in voltage. The current passed through the instability conduction region and entered into an extremely high conductivity region i.e. the conductivity is switched between two conductivity regions via an instability region $[\mathbf{9}, \mathbf{1 5}, \mathbf{1 7}]$. Switching field decreases with increase in sintering temperatures of all the samples are presented in Table 1. From table the switching field decreases with increase in sintering temperature, which is attributed to increase in grain size. The lattice constant decreases with decrease in switching field because the lattice dimension is dependence on switching field. The investigative /observed switching fields are very high as reported earlier [11, 16].

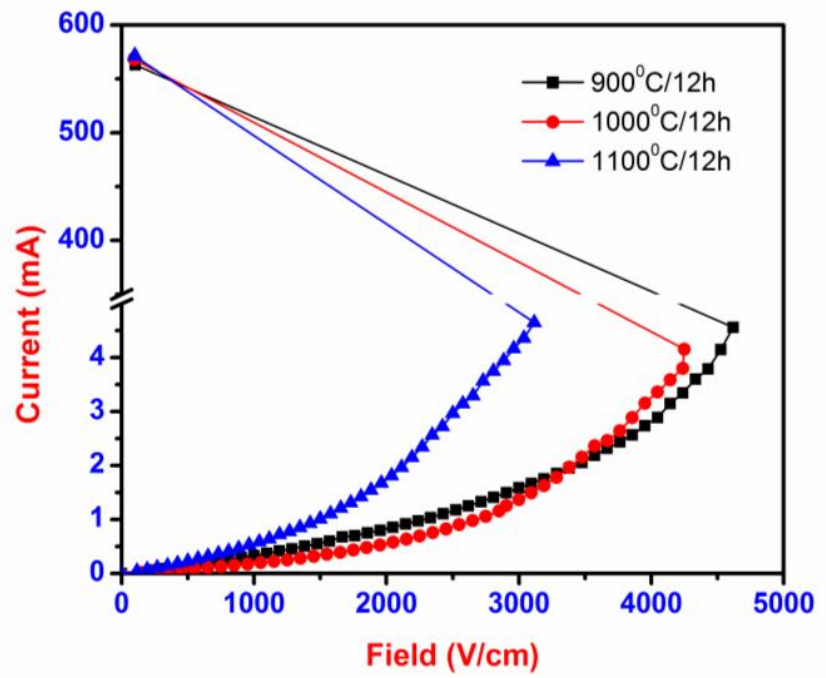

Fig. 5. Current Vs dc electrical field for Cd ferrite

The cadmium ferrites of different sintering temperatures are under investigation, when the cycle was repeated after two weeks. The result may be noted that there is no 'ageing effect' in this ferrite. The ferrite samples were subjected to a second cycle of switching, which was run immediately after the first cycle [17]. None of the models can satisfactorily explain the electrical switching in this system, the existence of SCL-current could be possible because of switching phenomenon [17].

\section{Conclusion}

Ferrite samples under investigation show single phase cubic spinel structure. The Lattice constant is found to decrease slightly while porosity and grain size increase with increasing sintering temperature. The crystallite size of the samples lies in the range 22.83 to $24.44 \mathrm{~nm}$. The absorption bands around $400 \mathrm{~cm}^{-1}$ and $600 \mathrm{~cm}^{-1}$ correspond to octahedral and tetrahedral sites. The CCNR type electrical switching is observed in the all samples under investigation. The electrical switching fields are decreases with increase in sintering temperature.

\section{Acknowledgements}

The authors are grateful to UGC New Delhi for financial assistance through the Major Research Project Ref. No- F.No.36-212/2008 (SR).

\section{Reference}

1. Gadkari, A. B.; Shinde, T. J.; Vasambekar, P. N. Mater. Charact. 2009, 60, 1328

DOI: $10.1016 /$ j.matchar.2009.06.010.

2. Desai R.; Mehta R. V.; Upadhyay R. V.; Gupta A.; Praneet A.; Rao K. V. Bull. Mater. Sci. 2007, 30(3), 197.

DOI: $10.1007 / \mathrm{s} 12034-007-0035-4$.

3. Sagare M. S.; Vaingankar A. S.; Kulkarni S. G. J. Phys. IV France 07 1997, C1-157.

DOI: $10.1051 /$ ip $4: 1997156$.

4. Tianshu Z.; Hing P.; Jiancheng Z.; Lingbing K. Mater. Chem. Phys. 1999, 61(3), 192

DOI: $10.1016 / \mathrm{S} 0254-0584(99) 00133-9$.

5. Bakuzis A. F.; K. Skeff Neto.; et al, Appl. Phys. lett. 2004, 84(13), 2355.

DOI: $10.1063 / 1.1690497$.

6. Yokoyama, M.; Sato, T.; Ohta, E. J. Appl. Physics 1996, 80, 1015. DOI: $10.1063 / 1.362834$.

7. Mostafa A. A.; El-Shobaky G.A.; Girgis E. J. Phys. D: Appl. Phys. 2006, 39, 2007.

DOI: $10.1088 / 0022-3727 / 39 / 10 / 004$.

8. Nayak P. K. Mater. Chem. Phys. 2008, 112, 24.

DOI: $10.1016 /$ j.matchemphys.2008.05.018.

9. Islam R.; Rahman. Md Obaidur.; Hakim A.M.; Saha D. K. Mater Sci. and Appli, 2012, 3, 326. DOI: $10.4236 / \mathrm{msa} .2012 .3508$

10. Yamashiro T. Jap. J. Appl. Phys. 1973, 12, 148 DOI: $10.1143 /$ JJAP.12.148.

11. Vaingankar A.S.; Kamble P.N.; Kulkarani V. R. Ind. J. Pur. Appl. Phys. 1990, 28(9), 508

12. Keizo H.; Nakayama, Kaoru Ohta, Keizo; Jap. J. Appli. Phys. 1973, 12(7), 1116. DOI: $10.1143 /$ JJAP.12.1116

13. Miller J. C.; Barker R. C. J. App. Phys. 1963, 34 (4), 1129. DOI: $10.1063 / 1.1729401$.

14. Babbitt R. W.; Sands G.; Dunlap A. J. App. Phys. 1969, 40(3), 1455. DOI: $10.1063 / 1.1657717$.

15. Tancrell Roger H.; McMahon, Robert E. J. App. Phys. 1960, 31(5), 762.

DOI: $10.1063 / 1.1735695$

16. Vasambekar P. N.; Kolekar C. B.; Vaingankar A. S. Mater. Res. Bull. 1999, 34(6), 863 .

DOI: $10.1016 / \mathrm{S} 0025-5408(99) 00081-1$.

17. Saija K. G.; Joshi U. S.; Lakhani V. K.; Modi K. B. J. Phys. D: Appl. Phys. 2009, 42, 165402. DOI: $10.1088 / 0022-3727 / 42 / 16 / 165402$.

18. Patange S. M.; Shirsath S. E.; Lohar K. S.; Jadhav S. S.; Mane D. R.; Jadhav K. M. J. Mater. Lett. 2010, 64(6), 722. DOI: $10.1016 /$ j.matlet.2009.12.049.

19. Patange S. M.; Shirsath S.; Lohar K. S.; Jadhav S.S.; Kulkarni N.; Jadhav K. M. Phys B: Cond. Matter. 2011, 406(3), 663. DOI: $10.1016 /$ j.physb.2010.11.081

20. Anima Johari.; Bhatnagar M. C.; Rana Vikas. Adv. Mat. Lett. 2012, 3(6), 515-518.

DOI: $10.5185 /$ amlett.2012.icnano.251. 
21. Pragna Kiri.; Geoff Hyett.; Russell Binions. Adv. Mat. Lett. 2010, 1(2), 86-105

DOI: $10.5185 /$ amlett.2010.8147

22. Cullity B. D.; Stock S. R. Elements of X-ray diffraction. Prentice Hall 2001.

23. Gadkari A. B.; Shinde T. J.; Vasambekar P. N. Rare Metels, 2010, 29(2), 168.

DOI: $10.1007 / \mathrm{s} 12598-010-0029-\mathrm{Z}$.

24. Wurst J. C.; Nelson J. A. J. Am. Ceram. Soc. Bull. 1972, 55, 109. DOI: $\underline{10.1111 / \mathrm{j} .1151-2916.1972 . t b 11224 .}$

\section{Advanced Materials Letters}

\section{Publish your article in this journal}

ADVANCED MATERIALS Letters is an international journal published quarterly. The journal is intended to provide top-quality peer-reviewed research papers in the fascinating field of materials science particularly in the area of structure, synthesis and processing, characterization, advanced-state properties, and applications of materials. All articles are indexed on various databases including DOAJ and are available for download for free. The manuscript management system is completely electronic and has fast and fair peer-review process. The journal includes review articles, research articles, notes, letter to editor and short communications.
JOURNAL

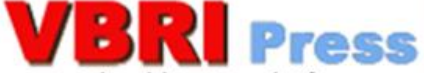

a rapid publication platform

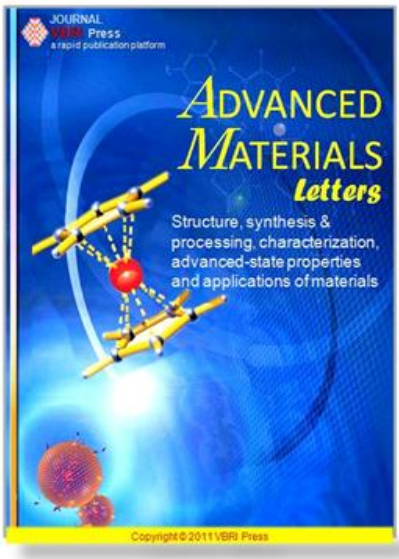

